\title{
Early Unemployment and Subsequent Career Complexity: A Sequence-Based Perspective
}

\author{
By Anna Manzoni and Irma Mooi-Reci*
}

\begin{abstract}
We aim to examine how previous unemployment affects future unemployment and career complexity over the life course. Theory suggests that unemployment triggers negative chains of 'low-pay-no-pay' circles. Using longitudinal data on men aged 18-64 from the German Socio-Economic Panel, we employ sequence-based methods to quantify career complexity and dynamic panel models to test our hypotheses about the process of cumulative disadvantage on employment careers for the previously unemployed workers over time. We find that unemployment 'breeds' unemployment and increases career complexity over the life course. However, unemployment at older ages leads to much higher career complexity than at younger ages.
\end{abstract}

JEL Classifications: J21; J60; J64

\section{Introduction}

In recent years, a considerable debate has arisen about the role played by trigger events (i.e., disruptive life course events such as childbirth, divorce, and unemployment) in generating patterns of social inequality (DiPrete, 2002; England/Budig, 2003; Gangl, 2004, 2006). Research suggests that trigger events in general, and unemployment in particular, cause a disproportionate drawback or 'scar' on subsequent labor market outcomes (Gangl, 2004; Jacobson et al., 1993; Gregg, 2001; Arulampalam et al., 2001).

Although much has been learned about the consequences of unemployment, a detailed understanding of the persistence of these scarring effects on workers' entire careers is not yet fully obtained. For instance, do previously unemployed workers recover from unemployment or does a single unemployment expe-

* An earlier version of this paper was presented at the $9^{\text {th }}$ SOEP Conference in Berlin, Germany. We thank the participants of the conference for their comments and suggestions. 
rience lead to persisting negative career spirals? The notion of 'vicious circles' captures the idea that socioeconomic consequences of early unemployment unfold through the process of cumulative disadvantage (DiPrete/Eirich, 2006). The assumption is that early unemployment may lead to or 'breed' future unemployment by setting up a negative chain of 'low-pay-no-pay' circles. Although a central element of the cumulative disadvantage theory, few studies have tried to empirically model entire career pathways in a dynamic and advanced way. This is important because early unemployment may affect employment careers as a whole, influencing not just the timing of a new unemployment spell, but also the sequencing and duration. By neglecting the fact that unemployment dynamics may take place over an extended period of time, existing research may underestimate the effects of unemployment on workers' entire employment careers leaving us with an incomplete picture about the 'true' effects of unemployment.

This paper aims to address this gap by examining how early unemployment affects workers' career pathways over their life course. We use the German Socio-Economic Panel data with waves spanning over the period 1984-2005 with particular attention on German working men between 18 and 64 years of age. We apply a sequence-based methodology to reveal entire employment trajectories and specifically examine the sequence of labor force states ${ }^{1}$ before and after a first unemployment experience. We develop and test hypotheses about the process of cumulative disadvantage on employment careers. Using a random-effect probit model, we examine whether early unemployment increases the probability of future unemployment. Using fixed effect regression instead, we investigate whether early unemployment leads to increasing career complexity compared to continuous employment. We end with a brief conclusion and implications for future research.

\section{The Cumulative Disadvantage of Unemployment}

Why does previous unemployment affect future employment? In the literature, two main explanations have been advanced to explain the negative effects of unemployment on future labor market prospects. The first relates to unemployment itself and the way it decreases future employability by depreciating human capital and readiness to work. While a spell of unemployment generates a direct drop in workers' incomes, it also leads to a depreciation of human capital, which grows as the unemployment period lengthens (Gregg, 2001; Heckman/Borjas, 1980). The depreciation of human capital decreases the chances

1 We specify four main states: employment, not employment, unemployment and retirement. 
of future employability by urging individuals to accept jobs of poorer quality, which in turn increase the risk of dismissal and make them more vulnerable to recurrent spells of unemployment. Repeated spells of unemployment affect future readiness to work and may in turn cause future unemployment spells that lead to downward job and earnings spirals. This causal relationship between past unemployment and present unemployment is often referred to in the literature as 'unemployment state dependence' (Narendranathan/Elias, 1993; Omori, 1997; Gregg, 2001). The second explanation relates to unemployment stigma: a past unemployment spell stigmatizes workers and influences the hiring decision of an employer who judges workers' productivity and performance by their employment history. As a result, those who have experienced unemployment are offered less secure jobs that lead to 'low-pay-no-pay' cycles (Jacobson et al., 1993; Arulampalam, 2001; Gregory/Jukes, 2004; Stevens, 1997; Stewart, 2000). These two mechanisms, however, may work differently in different institutional contexts. For instance, given the generosity in the level and duration of benefits in the German system, workers may afford longer unemployment periods. This may exacerbate the effects of human capital depreciation over time (Gangl, 2004, 2006). At the same time, the stigma related to unemployment may also be related to the norms and standards within a specific culture. For instance, in countries with a rigid labor market structure where older workers are highly protected, such as in Germany, unemployment at older ages may be less common resulting into higher stigma effects at older ages. On the other hand, in countries with more flexible labor market structures, where workers are hired and fired easily, young workers' "job-shopping" behavior may be much more accepted among employers and therefore constitutes less of a scar.

The established connection in the literature between early unemployment and the increasing future unemployment risk under specific institutional or normative contexts, demonstrates the manifestation of a cumulative disadvantage process. The idea of such a process is that the advantage or disadvantage of one group accumulates over that of another group leading to disproportionate inequalities between different social groups in the labor market (see for a review DiPrete/Eirich, 2006). We invoke mechanisms from the cumulative disadvantage theory to explain why and how unemployment may create labor market inequalities. We argue that a single unemployment spell may already increase workers' future likelihood to re-experience unemployment, but this accumulates further if unemployment is repeated. Such process makes it difficult for previously unemployed workers to catch up and creates disproportionate inequalities between equivalent groups of workers that differ only with respect to their previous (un)employment history. Furthermore, the effects of this process are not limited to a single state, but may influence the sequence and timing of subsequent transitions as well: a single unemployment spell not only increases the probability of recurrent unemployment, but may also make 
career pathways more complex (i.e., increasing the frequency of and the duration in specific labor force states). Finally, the impact of unemployment experienced at younger ages may accelerate even further if it is experienced again over time, at least because the recovery process after unemployment keeps being interrupted by additional unemployment spells. Accordingly, we formulate three hypotheses:

Hypothesis 1: An early unemployment experience will increase the exposure to future unemployment risks (unemployment state dependency hypothesis).

Hypothesis 2: The career trajectories of previously unemployed workers will increasingly grow in complexity compared to trajectories of those without previous unemployment.

Hypothesis 3: Those who experience unemployment at younger ages and then fall again into unemployment will have more complex career trajectories compared to those who experience it at later ages.

\section{Data and Methodology}

We use monthly data from the German Socio Economic Panel (SOEP) ${ }^{2}$ with waves spanning over the period 1984-2005. We consider respondents' - and in particular men's - careers between 18 and 64, ending up with a sample of 9,653 respondents, 7,634 of whom never experienced unemployment. Of the 2,019 who experienced unemployment at some point during the observation period, 290 do not have any other spell after unemployment, 1,729 respondents had a career trajectory after unemployment but only 1,391 also had a career trajectory before it, while 338 started their observation period in unemployment.

\section{Methodology}

We follow a twofold strategy: First, to obtain empirical evidence on the causal relationship between a past unemployment and the likelihood of re-experiencing unemployment, we apply random-effect dynamic models including lagged dependent variables on the right-hand side, so to examine what has been referred to as 'unemployment state dependence' (Maddala, 1987). The dependent variable is unemployment occurrence, specified as a binary variable, taking the value 1 if a respondent is unemployed and 0 if employed at time $t$ (mea-

2 The SOEP is a panel study that started in 1984, in which the same respondents are interviewed (mostly face-to-face) annually and asked information about their employment history (Frick, 2005). Data were provided by the German Institute for Economic Research. 
sured in months). Second, we create a measure of career complexity (Elzinga, 2010) using sequence-based methods, which treat the trajectory itself as the unit of analysis and focus on the sequential character of all labor force events together (Aisenbrey/Fasang, 2010). This is constructed as a time-varying variable indicating the complexity of the career up until $t$. We use this measure as a (second) dependent variable in the fixed-effects regression models correcting for observed and unobserved heterogeneity, to examine whether and how patterns of career complexity grow within persons over time.

We estimate our random effect model in two steps. A first baseline model (Model 1) includes only two covariates capturing unemployment history: lagged unemployment incidence (i.e. the number of unemployment spells one experienced in the career up until the previous month and lagged unemployment occurrence, that is a dummy for the unemployment status at $t-1$. In a second step (Model 2), we also include control variables capturing: socio-demographic characteristics (age, age squared, birth cohort, ${ }^{3}$ marital status, ${ }^{4}$ number of kids in the household); human capital (tenure; occupational status, ${ }^{5}$ education le$v e l^{6}$ ); business cycle effects (GDP change). To guard against the possibility that the error term is not independently distributed across individuals and time periods, we include the means of all time-varying covariates as additional regressors (Maddala, 1987).

The fixed-effect model is also estimated in two steps. A first baseline model (Model 1) includes only lagged unemployment occurrence as explanatory variable. In a second step (Model 2), we also include the same control variables as in the random effect model (2) and we additionally control for career fluctuations before unemployment including a variable indicating the (time-varying) turbulence of the career before the first unemployment experience. Furthermore, we introduce an interaction term between age at first unemployment (ranging between 18 and 64) and unemployment occurrence at $t-1$, to investigate whether there is a difference in the growth of the career complexity among respondents experiencing unemployment at different ages.

3 Birth cohort is specified as a categorical variable with 5 categories: $<1932$ (ref.); $1932-1945 ; 1946-1953 ; 1954-1963$ and 1964 and after.

4 The reference category in this case is married, while two additional categories are specified: single and divorced/widowed.

5 Tenure is measured in months and occupational status is measured using the International Socio-Economic Index (ISEI) scale of Ganzeboom et al. (1992). They refer to the current job in case of employment and to the last job in case of unemployment.

6 Education is measured with the CASMIN classification and is specified as a categorical variable with low education (1a, 1b and 1c) as reference and additional categories for low intermediate ( $2 \mathrm{~b}$ and $2 \mathrm{c}$ ), high intermediate ( $2 \mathrm{c}$ gen and $2 \mathrm{c} v \mathrm{vo}$ ) and tertiary education ( $3 a$ and $3 b)$. 


\section{The Measure of Career Complexity}

We employ, as measure of career complexity, a recently developed measure of complexity (Elzinga, 2010), also referred to as 'turbulence' (Elzinga/Liefbroer, 2007). This takes into account the order of career states and quantifies the number of employment changes as well as the duration variation in different states $^{7}$ (Biemann et al., 2009). This implies that the more transitions and the higher the variation in the time spent in each state, the more complex careers are. Such measure captures career instability, which is one important predictor of workers' career success or failure.

\section{Results}

Table 1 summarizes estimations from the two random-effect probit models. Due to space limitations, we focus on Model 2. Results confirm our first hypothesis that an early unemployment experience would increase the probability of future unemployment. We find that, all else equal, a respondent who was unemployed in the previous month $(t-1)$ has on average 3.422 points higher probability of experiencing unemployment at time $t$ relative to those who were not unemployed the month before. Moreover, each additional unemployment spell increases the probability of becoming unemployed by 0.078 points. These results imply that the probability of re-experiencing unemployment in the future is persistent and higher among those with more unemployment spells in the past.

Table 2 shows the results of the fixed-effect regression models. Model 2 shows that, in line with the expectations from our second hypothesis, all else equal and controlling for career fluctuations before unemployment, previously unemployed workers experience an increasing career complexity over time compared to those in continuous employment, which implies an increasing number of changes and variation in spell durations. The interaction term between age at first unemployment and unemployment occurrence at $t$ - 1 indicates that, contrary to our expectations (hypothesis 3 ), careers become more complex when workers experience their first unemployment at older ages: the effect of a previous unemployment experience on career complexity is 0.055 points higher

7 As a measure of turbulence of sequence $x$ of duration $t$, Elzinga (2007:33) proposed using $0 \leq T(x, t)=\log _{2}\left(\phi(\mathrm{x}) \frac{\mathrm{s}_{\mathrm{t}, \max }^{2}+1}{\mathrm{~s}_{\mathrm{t}}^{2}+1}\right)$, with $\phi(x)$ denoting the number of distinct subsequences, $s_{t}^{2}$ denoting the variance of state durations and $s_{t, \max }^{2}$ the maximum of that variance given the total duration of the sequence. $T(x, t)$ is therefore a sequence property quantified such that the sequencing of the states and the variance of their durations is taken into account; it is not sensitive to the specific time scale used and it increases with decreasing variance of the durations of the states (Elzinga/Liefbroer, 2007). 
Table 1

Random-Effect Probit Model for the Probability of Unemployment Occurrence

\begin{tabular}{|lcc|}
\hline & Model 1 & Model 2 \\
\hline Unemployment Incidence (T-1) & $0.013^{* *}$ & $0.079^{* * *}$ \\
Unemployment Occurrence (T-1) & $(2.24)$ & $(11.29)$ \\
& $3.455^{* * *}$ & $3.422^{* * *}$ \\
Constant & $(211.39)$ & $(205.48)$ \\
& $-3.058^{* * *}$ & $-1.378^{* * *}$ \\
Observations & $(145.33)$ & $(-7.73)$ \\
Number of Respondents & 730114 & 727048 \\
\hline
\end{tabular}

Source: Authors' calculations based on the SOEP data, 1984-2005.

Note: ${ }^{* *} \mathrm{p}<0.05 ; * * * \mathrm{p}<0.001 ; z$-values are in parentheses. Model 2 includes controls for age, age squared, birth cohort, marital status, number of children, tenure, occupational status, education, GDP change as well as the mean of all the time-varying variables.

for each additional year of age at which first unemployment is experienced. This implies that if unemployment occurs at younger ages it may have less deteriorating effects on future career trajectories than when it occurs at older ages. One possible explanation may relate to the fact that employers may perceive unemployment at older ages as a negative signal and may label workers as less productive and less committed to work, while unemployment tends to be more socially accepted for young people. An alternative explanation might

\section{Table 2}

Fixed Effect Regression Model for the Development of Career Complexity

\begin{tabular}{|lcc|}
\hline & Model 1 & Model 2 \\
\hline Unemployment Occurrence (T-1) & $1.226^{* * *}$ & $-1.967^{* * *}$ \\
Age at First Unemployment & $(42.62)$ & $(-45.27)$ \\
Un. Occurrence (T-1) X Age at First Un. & & - \\
& & $0.055^{* * *}$ \\
Constant & $-8.197 * * *$ & $-48.979^{* * *}$ \\
& $(1852.34)$ & $(-683.55)$ \\
Observations & 730114 & 727048 \\
Number of Respondents & 8895 & 8675 \\
R-Squared & 0.25 & 72.04 \\
\hline
\end{tabular}

Source: Authors' calculations based on the SOEP data, 1984-2005.

Note: ${ }^{* *} \mathrm{p}<0.05 ; * * * \mathrm{p}<0.001 ; t$-values are in parentheses. Model 2 includes controls for age, age squared, birth cohort, marital status, number of children, tenure, occupational status, education, GDP change as well as the mean of all the time-varying variables. 
refer to the unwillingness of employers to hire someone who might stay in employment for a short time only (due to approaching retirement age), which might also negatively affect the employment prospects of older people. Furthermore, it should be considered that young people have more time to recover from a negative event (such as unemployment may be), and for this reason its consequences might be not that bad. Also, older workers might be forced into lower/unsecure jobs, which leads to a vicious circle and additional worsen their employment prospects, just because they need any sort of job. Younger people, instead, might still get some support from their parents, so that they can wait for a better job, avoiding a vicious circle, or they could invest more in their education (given parents' support).

\section{Conclusion and Discussion}

This article aimed to examine whether previous unemployment 'breeds' future unemployment and how it affects career complexity over the life course. The literature suggests that negative events, like unemployment, can lead to vicious career circles over time. Drawing on previous empirical evidence on unemployment scarring and using insights from the cumulative disadvantage theory, we developed hypotheses about the cumulating disadvantageous effects of unemployment on future unemployment and career complexity. We argued that if unemployment 'bred' unemployment, unemployment scarring effects would not only persist but also increase career complexities over time. Using longitudinal data from the GSOEP, we employed sequence based methods to quantify career complexity and employed dynamic panel models to test our hypotheses. We found that unemployment not only 'breeds' unemployment but also increases career complexity over the life course, indicating that it not only affects a single state but also entire career trajectories. Contrary to our expectations, we found that unemployment leads to a far larger increase in career complexity when experienced at older ages.

Our findings regarding workers' career complexity are a first attempt to capture the effect of unemployment on the entire career, but more research is needed to provide a long-term assessment of what drives the cumulative disadvantageous effects of unemployment. Our analyses (not shown but available upon request) showed that a series of complex career trajectories emerge after unemployment. However, the circumstances under which complex trajectories emerge as well as of the factors which drive such deviating career pathways are still not fully clear. Our analyses were limited to men: it would be interesting to reveal the cumulative disadvantage nature of unemployment on women's careers. 


\section{References}

Arulampalam W. (2001): Is Unemployment Really Scarring? Effects of Unemployment Persistence on Wages, Economic Journal 111, 585-606.

Biemann, T./Fasang, A./ Grunow, D. (2009): Does economic globalization or industry growth destabilize careers? An analysis of career complexity and career patterns over time, CIQLE working paper 2009-2.

Budig, M./England, P. (2001): The Wage Penalty for Motherhood, American Sociological Review 66: 204-225.

DiPrete, T. A. (2002): Life course risks, mobility regimes and mobility consequences: A comparison of Sweden, Germany and the United States, American Journal of Sociology 108, 267-309.

DiPrete, T. A./Eirich, G. M. (2006): Cumulative Advantage as a Mechanism for Inequality: A Review of Theoretical and Empirical Developments, Annual Review of Sociology 32, 271-297.

Heckman, J./Borjas, G. (1980): Does unemployment cause future unemployment? Definitions, questions and answers from a continuous time model of heterogeneity and state dependence, Economica 47, 247-83.

Elzinga, C. H. (2010): Complexity of Categorical Time Series, Sociological Methods \& Research 38, 463.

Elzinga, C. H. (2007): CHESA 2.1 User manual. Amsterdam, Vrije Universiteit Amsterdam.

Elzinga, C. H./Liefbroer, A. C. (2007): De-standardization and differentiation of family life trajectories of young adults: A cross-national comparison, European Journal of Population 23, 225-250.

Frick, J. (2005): A General Introduction to the German Socio-Economic Panel Study (SOEP). Design, Contents and Data Structure [waves A-U, 1984-2004].

Gangl, M. (2004): Welfare states and the scar effects of unemployment: A comparative Analysis of the United States and West Germany, American Journal of Sociology 109, $1319-1364$.

Gangl, M. (2006): Scar Effects of Unemployment: An Assessment of Institutional Complementarities, American Sociological Review 71, 986-1013.

Ganzeboom, H./DeGraaf, P./Treiman, D. J. (1992): A Standard International SocioEconomic Index of Occupational Status, Social Science Research 21, 1-56.

Gregg, P. (2001): The impact of youth unemployment on adult employment in the NCDS. Economic Journal 111, 623-53.

Gregory M./Jukes R. (2001): Unemployment and Subsequent Earnings: Estimating Scarring among British Men 1984-94, Economic Journal 111, 607-625.

Jacobson, L./LaLonde, R. / Sullivan, D. (1993): Earnings losses of displaced workers, American Economic Review 83, 685-709. 
Maddala, G. S. (1987): Limited Dependent Variable Models Using Panel Data, Journal of Human Resources 22 (3), 305-338.

Merton, R. K. (1973): The Matthew effect in science, in: N.W. Storer (ed.), The Sociology of Science, 439-59, Chicago.

Narendranathan, W./Elias, P. (1993): Influences of past history on the incidence of youth unemployment: Empirical findings for the UK, Oxford Bulletin of Economics and Statistics55: $161-85$.

Omori, Y. (1997): Stigma effects of nonemployment, Economic Inquiry 35, 394-416.

Stevens, A. H. (1997): Persistent effects of job displacement: the importance of multiple job losses, Journal of Labor Economics 15, 165-88.

Stewart, M. (2000): The inter-related dynamics of unemployment and low pay, University of Warwick, mimeo. 